\title{
The Mechanism of Starch
} Over-Accumulation in Chlamydomonas reinhardtii High-Starch Mutants Identified by Comparative Transcriptome Analysis

\author{
Kwang M. Koo ${ }^{1,2}$, Sera Jung ${ }^{1}$, Beom S. Lee ${ }^{1}$, Jin-Baek Kim ${ }^{1}$, Yeong D. Jo', \\ Hong-Il Choi ${ }^{1}$, Si-Yong Kang ${ }^{1}$, Gook-H. Chung ${ }^{2}$, Won-Joong Jeong ${ }^{3 *}$ and \\ Joon-Woo Ahn ${ }^{1 *}$
}

${ }^{1}$ Advanced Radiation Technology Institute, Korea Atomic Energy Research Institute, Jeongeup, South Korea, ${ }^{2}$ Department of Biological Sciences, Chonbuk National University, Jeonju, South Korea, ${ }^{3}$ Molecular Biofarming Research Center, Korea Research Institute of Bioscience and Biotechnology, Daejeon, South Korea

OPEN ACCESS

Edited by:

Weiwen Zhang,

Tianjin University, China

Reviewed by:

Song Xue,

Dalian Institute of Chemical Physics

(CAS), China

Jon Pittman,

University of Manchester

United Kingdom

${ }^{*}$ Correspondence:

Joon-Woo Ahn

joon@kaeri.re.kr

Won-Joong Jeong

wonjoong@kribb.re.kr

Specialty section:

This article was submitted to

Microbial Physiology and Metabolism,

a section of the journal

Frontiers in Microbiology

Received: 12 October 2016

Accepted: 27 April 2017

Published: 23 May 2017

Citation:

Koo KM, Jung S, Lee BS, Kim J-B,

Jo YD, Choi H-I, Kang S-Y,

Chung G-H, Jeong $W-J$ and Ahn J-W (2017) The Mechanism

of Starch Over-Accumulation

in Chlamydomonas reinhardtii

High-Starch Mutants Identified by

Comparative Transcriptome Analysis.

Front. Microbiol. 8:858.

doi: 10.3389/fmicb.2017.00858
The focus of this study was the mechanism of starch accumulation in Chlamydomonas reinhardtii high-starch mutants. Three $C$. reinhardtii mutants showing high-starch content were generated using gamma irradiation. When grown under nitrogen-deficient conditions, these mutants had more than twice as much starch than a wild-type control. The mechanism of starch over-accumulation in these mutants was studied with comparative transcriptome analysis. In all mutants, induction of phosphog/ucomutase 1 (PGM1) expression was detected; PGM1 catalyzes the inter-conversion of glucose 1-phosphate and glucose 6-phosphate in both starch biosynthetic and glycolytic pathway. Interestingly, transcript levels of phosphoglucose isomerase 1 (PG/1), fructose 1,6-bisphosphate aldolase 1 and 2 (FBA1 and FBA2) were down-regulated in all mutants; PGl1, FBA1, and FBA2 act on downstream of glucose 6-phosphate conversion in glycolytic pathway. Therefore, down-regulations of $P G / 1, F B A 1$, and FBA2 may lead to accumulation of upstream metabolites, notably glucose 6-phosphate, resulting in induction of $P G M 1$ expression through feed-forward regulation and that PGM1 overexpression caused starch over-accumulation in mutants. These results suggest that PGI1, FBA1, FBA2, and PGM1 correlate with each other in terms of coordinated transcriptional regulation and play central roles for starch over-accumulation in C. reinhardtii.

Keywords: starch biosynthesis, glycolysis, comparative transcriptome analysis, microalgae, Chlamydomonas reinhardtii

\section{INTRODUCTION}

The energy demands of the world are large and increasing and, for many reasons, cannot be met by traditional energy sources alone. Bioenergy is a promising alternative source of energy, particularly appealing as it is renewable. Biofuels are mostly obtained from food crops (Chisti, 2007; Sharma et al., 2012). However, because their production requires cultivable land, producers of bioenergy crops are in competition with food growers for agricultural lands. Microalgae have potential as a source for bioethanol and biodiesel (Chisti, 2007; de Faria Silva and Bertucco, 2016), 
and their growth does not require agricultural land (Li et al., 2008). These organisms produce a larger amount of biomass than do crop plants and green algae also produce starch, which can be used as the production of bioethanol (Doana et al., 2012).

Starch is a polysaccharide, a storage form of carbohydrate that is present in plastids, produced in the chloroplasts of higher plants and some algae during photosynthesis. Starch is composed of amylopectin and amylose. Amylopectin, a branched chain of glucose units, is the major component of starch. The other molecule that comprises starch is amylose, which can be helical or linear (Buleon et al., 1998). Starch biosynthesis has been widely studied in many plants, including the unicellular green alga Chlamydomonas reinhardtii (Buleon et al., 1998; Streb and Zeeman, 2012; Busi et al., 2015). To explore molecular mechanisms of starch and lipid biosynthesis in response to nitrogen deprivation in C. reinhardtii, transcriptomic and proteomic analysis were performed using starchless mutant sta6; this mutant displayed up-regulation of both glyoxylate and gluconeogenesis pathway under nitrogen starvation, which resulted in over-accumulation of TAG (Blaby et al., 2013; Goodenough et al., 2014; Schmollinger et al., 2014). In addition, systems biology analysis for $C$. reinhardtii in response to nitrogen starvation was reported by Park et al. (2015), which provided fundamental insight for starch and TAG biosynthesis. Schulz-Raffelt et al. (2016) reported starch degradation 1 (std1) mutant showed hyper-accumulation of both starch and TAG under photoautotrophic condition under nutrient deprivation. C. reinhardtii produces starch by photosynthetic carbon fixation under phototrophic condition and also uses carbon-reduced compounds such as acetate under heterotrophic and mixotrophic condition (Johnson and Alric, 2013). There are two pathways for acetate assimilation to synthesis acetyl coenzyme A (Acetyl-CoA) in C. reinhardtii; acetyl-CoA synthetase (ACS) only involves in the one step conversion, or both acetate kinase (ACK) and phosphate acetyltransferase (PAT) participate in the two step conversion (Harris, 2009; Spalding, 2009; Johnson and Alric, 2013).

The glycolysis pathway, common to all cells, converts glucose to pyruvate. Several enzymes in the upper steps of the glycolysis pathway also participate in starch biosynthesis (Denis and Greyson, 1987). The glycolytic pathway is made up of three stages (Berg et al., 2002). In stage 1, glucose is converted to fructose 1,6-bisphosphate through three steps: phosphorylation, isomerization, and another phosphorylation. In stage 2, fructose 1,6-bisphosphate is cleaved into two three-carbon molecules. Finally, in stage 3 , the three-carbon compounds are oxidized to pyruvate, generating ATP. In non-plants, glycolysis occurs in the cytoplasm; in plants, it takes place in both the cytoplasm and plastids. In higher plants, sucrose and starch are required as substrates for cytosolic and plastidic glycolysis, respectively (Plaxton, 1996). Some of the enzymes for cytosolic glycolysis do not appear to be present in many green algae species, which implies that sucrose is relatively less important compound for carbon flux in green algae (Singh et al., 2008).

In the present study, the molecular mechanism of starch over-accumulation was investigated using C. reinhardtii mutants displaying high-starch content through comparative transcriptome analysis. Key genes that regulate starch biosynthesis and glycolysis/gluconeogenesis for starch over-accumulation were identified. This comparative transcriptome study also offers fundamental information about starch biosynthesis and glycolysis/gluconeogenesis in green algae.

\section{MATERIALS AND METHODS}

\section{Mutant Generation and Culture Conditions}

High-starch C. reinhardtii mutants (Sm142, Sm162, and Sm181) were used in this study, which were generated from C. reinhardtii strain cc124 (wild-type) by gamma irradiation. For generation of high-starch mutants, C. reinhardtii wild-type (strain cc124) cells grown in liquid Tris-acetate-phosphate (TAP) medium (Harris, 2009) were treated with 100 Gy gamma radiation for $1 \mathrm{~h}$. The irradiated cells were spread onto solid TAP media and incubated for 10 days at $25^{\circ} \mathrm{C}$ under dim light. Over 500 colonies grown in TAP media were transferred onto solid nitrogendeficient TAP (TAP-N; $\mathrm{NH}_{4} \mathrm{Cl}$ was replaced with $\mathrm{KCl}$ ) media and incubated for 5 days to induce starch accumulation. To select high-starch mutant candidates, iodine vapor staining for colonies was performed. For selected mutant candidates, starch contents were analyzed using starch assay kit as mentioned below. For liquid culture used in this study, approximately $1 \times 10^{5}$ cells were inoculated to $50 \mathrm{ml} \mathrm{TAP}$ medium. Culture was shaken continuously at $150 \mathrm{rpm}$ at $25^{\circ} \mathrm{C}$ under constant white light $\left(40 \mu \mathrm{mol} \mathrm{m}^{-2} \mathrm{~s}^{-1}\right)$. For treatment of nitrogen starvation, 5 -day-old sample grown in TAP medium was transferred to TAP-N medium and then cultured for 7 days under same condition as mentioned above. Siaut et al. (2011) reported that starch accumulation was rapidly increased for $2 \sim 3$ days and then gradually induced until day 7 after treatment of nitrogen deprivation. So, in this study, two time points (at days 2 and 7) were used to identify effect of nitrogen starvation on starch accumulation in C. reinhardtii mutants.

\section{Analysis of Transmission Electron Microscopy}

Three-day-old cells grown in nitrogen-deficient TAP media were washed with $250 \mathrm{mM}$ phosphate buffer ( $\mathrm{pH}$ 7.0). Fixation was carried out using $1 \%(\mathrm{v} / \mathrm{v})$ osmium tetroxide and $2.5 \%(\mathrm{v} / \mathrm{v})$ glutaraldehyde. Graded ethanol series (50-100\%) were utilized for dehydration. After dehydration, samples were embedded in Spurr's resin and thin sections prepared using an ultramicrotome (Ultracut UCT, LEICA, Germany). Specimens were observed using a transmission electron microscope (TEM; Tecnai, FEI, Netherlands).

\section{Measurements of Growth Rate and Starch Content}

Samples grown in nitrogen-deficient TAP media for 3 days were used. Starch content was evaluated using Starch assay kit (Sigma, St. Louis, MO, USA) according to manufacturer's instruction. 
For measurement of growth rate, approximately $1 \times 10^{5}$ cells were inoculated in $50 \mathrm{ml}$ of TAP medium and incubated under the same condition as mentioned above. Optical density (OD) at $750 \mathrm{~nm}$ was measured every $24 \mathrm{~h}$ using a spectrophotometer (Shimazu, Kyoto, Japan).

\section{RNA Isolation}

For RNA extraction, samples were taken at days 3 and 7 after transfer samples to nitrogen-deficient TAP media. Approximately $1 \times 10^{7}$ cells were used for RNA extraction for each sample. RNA was extracted using TRIzol reagent (Invitrogen, Carlsbad, CA, USA) according to the manufacturer's instructions. To remove genomic DNA contamination, one unit of RNase-free DNase (Takara, Kyoto, Japan) was treated to the total RNA for $30 \mathrm{~min}$. RNA samples were purified according to the manufacturer's instructions.

\section{RNA Sequencing and Data Analysis}

Three biological replicates of each sample grown in nitrogendeficient condition were prepared. Procedure of RNA isolation was followed as mentioned above. RNA-Seq paired end libraries were prepared using the Illumina TruSeq RNA Sample Preparation Kit v2 (Illumina, San Diego, CA, USA) according to the manufacturer's instruction. The constructed library was quantified using the KAPA library quantification kit (Kapa Biosystems, Wilmington, MA, USA) following the manufacturer's protocol. cDNA libraries were sequenced with Illumina HiSeq2000 (San Diego, CA, USA). To generate unigene sequences, total RNA (10 $\mu \mathrm{g})$ from each sample was prepared for creating a normalized cDNA and then amplified according to the Illumina RNA-seq protocol. Sequencing was carried out using Illumina HiSeq2000. Sequence data (quality of bp is upper than $\mathrm{Q}$ he) were selected using SolexaQA. All sequence reads from different samples were utilized to optimize the de novo assembly using the software Velvet (Zerbino and Birney, 2008) and Oases (Schulz et al., 2012). Transcripts of unigenes assembled with the total reads were validated by comparison with $C$. reinhardtii transcript sequences in Phytozome v11 (Plant Comparative Genomics portal of the Department of Energy's [USA] Joint Genome Institute $\left.^{1}\right)$ using BLASTx $\left(e\right.$-value $\left.\leq 1 \mathrm{e}^{-10}\right)$. For short read mapping, reads were mapped to the assembled unigenes using the bowtie software (Langmead et al., 2009). The number of mapped clean reads for each assembled unigene was counted and then normalization of DESeq package performed (Anders and Huber, 2010). Identification of differentially expressed genes (DEGs) between a control and mutants was conducted using fold change and $t$-test data. False discovery rate (FDR) was applied to identify the threshold of the $p$-value in multiple tests using DESeq. Correlation and hierarchical clustering analysis were carried out via AMAP library in R. Functional enrichment analysis for Gene Ontology (GO) and KEGG pathway were conducted using Gene Ontology Database and DAVID $^{2}$, respectively (Huang et al., 2009).

\footnotetext{
${ }^{1}$ http://www.phytozome.net/

${ }^{2}$ http://david.abcc.ncifcrf.gov/tools.jsp
}

\section{Quantitative Reverse Transcription-PCR Analyses}

Reverse transcription (RT) were performed using $5 \mu \mathrm{g}$ total RNA with 200 units of superscript ${ }^{\circledR}$ III reverse transcriptase (Invitrogen, Carlsbad, CA, USA), according to manufacturer's instruction. For quantitative RT-PCR, cDNA was amplified by SYBER Premix Ex Taq ${ }^{\mathrm{TM}}$ II (Takara, Kyoto, Japan) using CFX ${ }^{\mathrm{TM}}$ Real-Time System (Bio-Rad, Hercules, CA, USA). Reactions were carried out with the following program: 40 cycles at $92^{\circ} \mathrm{C}$ for $20 \mathrm{~s}$, at $55-60^{\circ} \mathrm{C}$ for $20 \mathrm{~s}$ and at $72^{\circ} \mathrm{C}$ for $20 \mathrm{~s}$. To confirm maximum efficiency of PCR, standard curve analysis was conducted using serial dilutions of primer pairs. Primer sequences are as follows: PGM1, 5'-GAT TAC GAG GAG TGC GCC AG-3' and 5'-GGG AGC CAT CTG TGA ACA CG-3'; ACS2, 5'-TGC TGC TGG GCT GTG CAT GA- $3^{\prime}$ and $5^{\prime}$-ACG CAG ACA CGA GCG GCT CT-3'; ACS3, 5' -TGA TAA ATT GTC ACG TCG TT- ${ }^{\prime}$ and $5^{\prime}$ GCC TAA ACG GGC CTA GTC-3'; FBA1, 5'-ATT TTG GGA

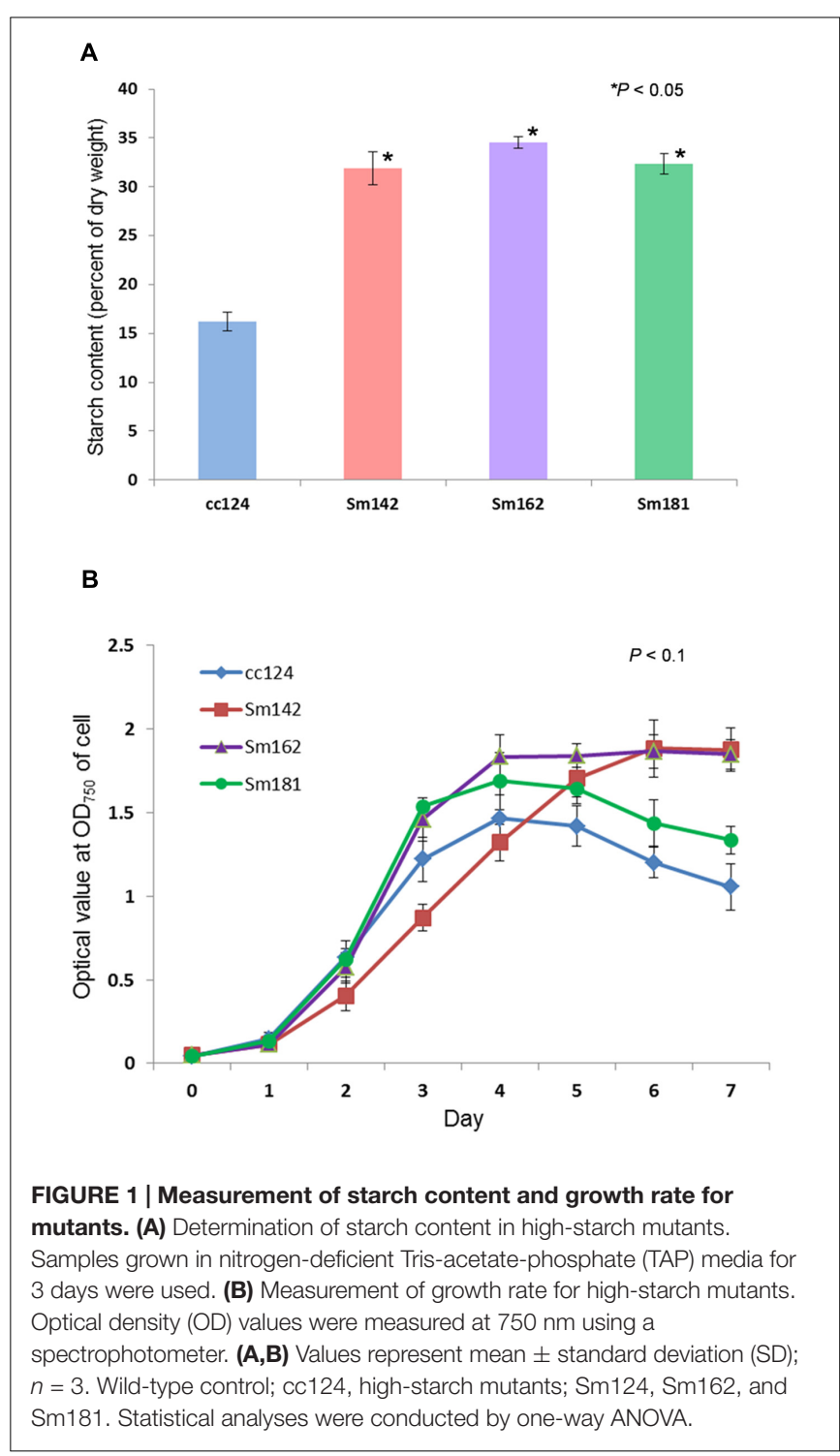


GAG AGC GTT GAG- $3^{\prime}$ and $5^{\prime}$-ACA ACA CCA GCA CAA AGC AC-3'; FBA2, 5'-CAG AGC AAC TGC AAC GAG AG-3' and $5^{\prime}$-GCA CTT CAT CCC TGC TCT TC-3'; STA1, 5'-AAC GCC GAC ATC ACC ATC- $3^{\prime}$ and $5^{\prime}-$ TCT TGA ACA CGT AGA TGC CC-3'; STA3, 5'-TTC ATC GAG CCC AAG AAC G- $3^{\prime}$ and $5^{\prime}$-AGT TGA GGT TGT GGA TGG TG-3'; STA6, $5^{\prime}$-CGT CTG TAT CCT CTG ACC AAG- $3^{\prime}$ and $5^{\prime}$-TGG GTG AGG CAG TAA ATC TTG-3'; TubA, $5^{\prime}$-CTC GCT TCG CTT TGA CGG TG-3' ${ }^{\prime}$ and $5^{\prime}$-CGT GGT ACG CCT TCT CGG C-3'. Specificity of PCR products was tested by melting curve analysis and gel electrophoresis. TubA was served as an internal control. Normalization and quantification were performed using Bio-Rad CFX manager 3.1 program (Bio-Rad, Hercules, CA, USA).

\section{Statistical Analyses}

Statistical analyses for quantitative RT-PCR and growth measurement were performed with one-way analysis (ANOVA) using R program (version $3.25^{3}$ ).

\section{RESULTS}

\section{Identification for Starch Over-Accumulation in Mutants}

Chlamydomonas reinhardtii mutants showing high-starch contents were generated from C. reinhardtii strain cc124 (wild-type) after $100 \mathrm{~Gy}$ gamma irradiation (data not shown). Each mutant contained specific mutations compared to $\mathrm{cc} 124$

${ }^{3} \mathrm{http} / / /$ www.r-project.org/ control, which was analyzed using transcriptome in/del analysis (Supplementary Table 1). Three mutants (Sm142, Sm162, and Sm181) displayed more than twice the amount of starch than cc124 wild-type control under nitrogen deprivation (Figure 1A). All mutants also showed higher starch contents than cc124 wild-type grown in nitrogen-replete condition (TAP media) for 5 days (data not shown). To determine growth rates of these mutants in TAP media, ODs were measured every 24 h for 7 days. Sm162 and Sm181 displayed similar growth rate with $\mathrm{cc} 124$ control until day 2, whereas Sm162 showed lower OD value than cc124 control until day 4 (Figure 1B). In the stationary phase, all mutants had greater OD values than a wild-type control. To identify morphological variation on starch accumulation in high-starch mutants, TEM analysis was also conducted (Figure 2). All mutants grown in nitrogen-deficient TAP media for 3 days accumulated large number of starch granules compared to cc124 control.

TABLE 1 | Total number of trimmed and mapped reads for control and each mutant grown in nitrogen-deficient condition.

\begin{tabular}{lccc}
\hline Sample & Total trimmed reads* & Mapped read & Mapped rate (\%) \\
\hline cc124 & $20,527,427$ & $19,813,851$ & 96.5 \\
sm142 & $18,584,829$ & $17,785,911$ & 95.7 \\
sm162 & $19,517,890$ & $18,748,577$ & 96.1 \\
sm181 & $13,033,402$ & $12,554,252$ & 96.3
\end{tabular}

*All trimmed read were summed from the three biological replicates of each sample.

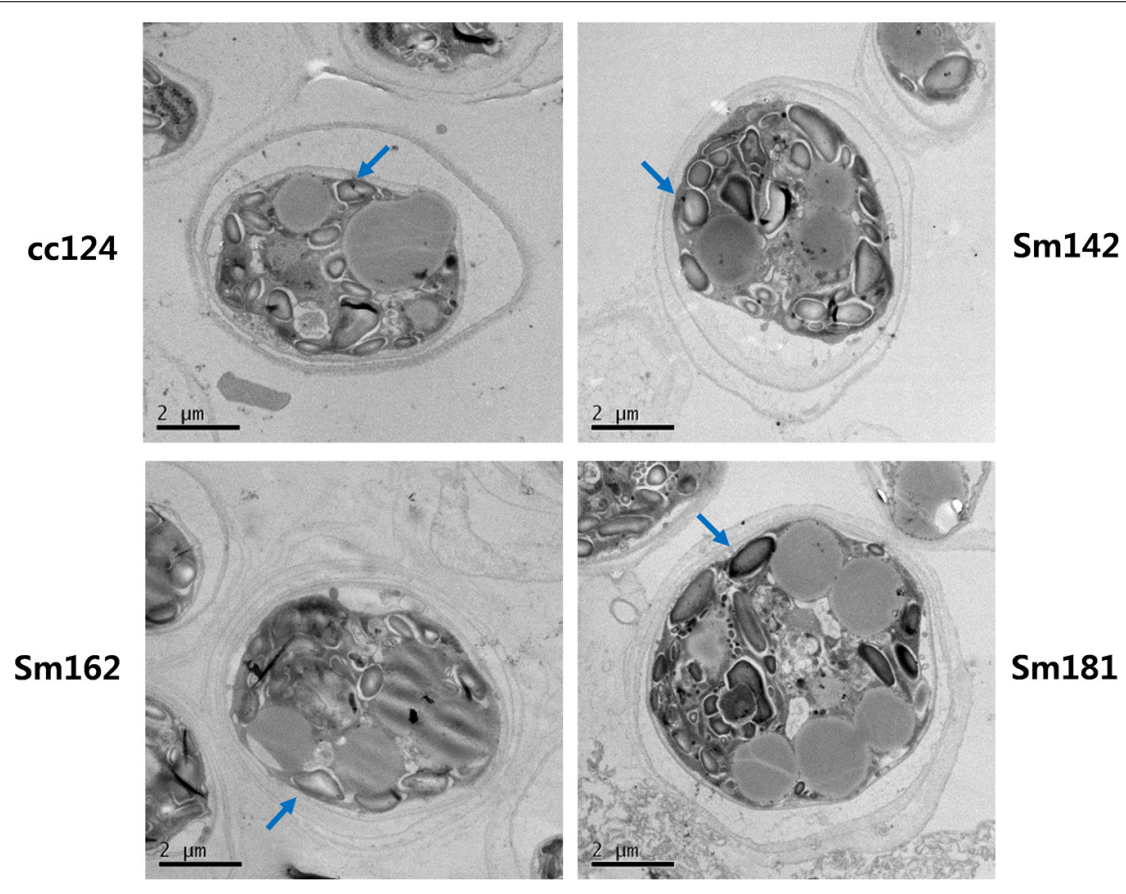

FIGURE 2 | Accumulation of starch granule in high-starch mutant cells. Ultrastructure of mutant cells by TEM analysis. Arrows indicate starch granule. Mutants and wild-type cultured in nitrogen-deficient TAP media for 3 days were used. Wild-type control; cc124, high-starch mutants; Sm124, Sm162, and Sm181. 
A

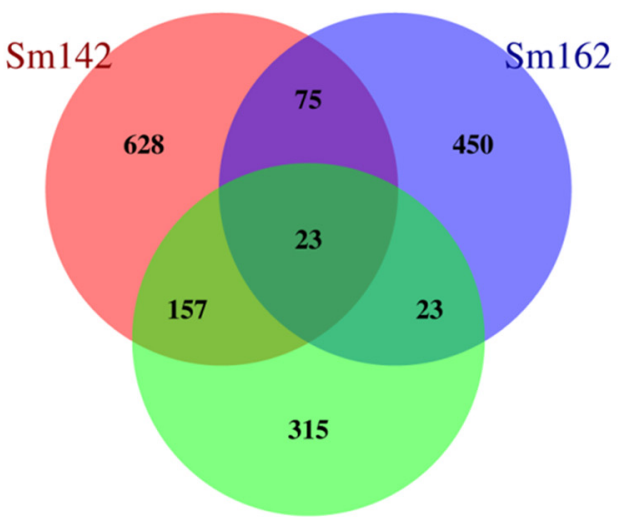

Sm181
B

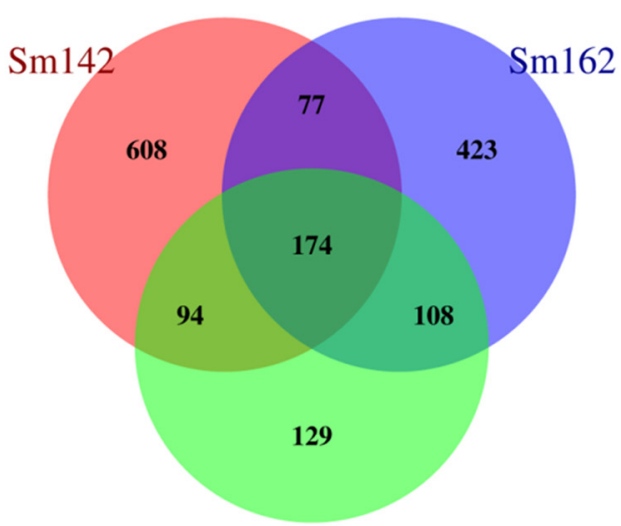

$\operatorname{Sm} 181$

C

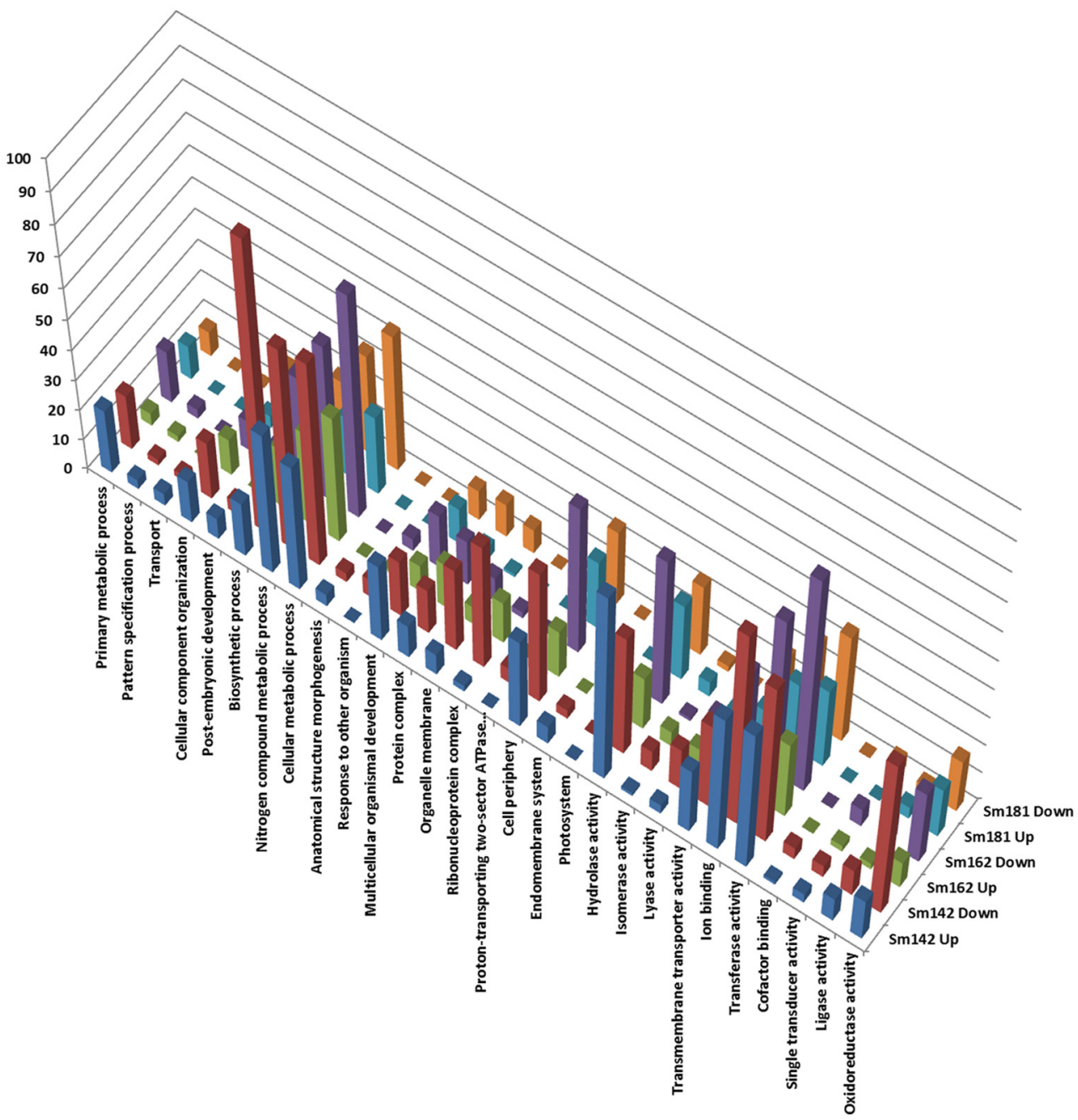

FIGURE 3 | Comparative differentially expressed genes (DEGs) analysis between high-starch mutants. (A-C) Venn Diagrams display number of up- and down-regulated DEGs in mutants compared to cc124 control. Samples were grown in nitrogen-deficient TAP media for 3 days. (A) Number of up-regulated genes. (B) Number of down-regulated genes. (C) GO analysis of up- and down-regulated DEGs. 


\begin{tabular}{|c|c|c|c|c|c|c|}
\hline \multirow{2}{*}{ Gene } & \multicolumn{3}{|c|}{ Day 3} & \multicolumn{3}{|c|}{ Day 7} \\
\hline & Sm142 & Sm162 & Sm181 & Sm142 & Sm162 & Sm181 \\
\hline AGPase & 0.13 & -0.07 & 0.17 & 0.16 & 0.03 & 0.74 \\
\hline$A G L I$ & 0.77 & -0.88 & 0.05 & 0.21 & -0.81 & -0.12 \\
\hline$A M Y A^{*}$ & 0.49 & -0.4 & 0.24 & 0.7 & -0.03 & 0.72 \\
\hline AMYAI & -0.88 & -1.51 & -0.11 & -0.6 & -1.16 & -0.55 \\
\hline$A M Y A 2$ & -0.39 & -0.34 & -0.37 & -0.39 & -0.84 & -0.65 \\
\hline$A M Y B I$ & -0.5 & -0.96 & -0.46 & -0.3 & -0.78 & -1.01 \\
\hline AMYB2 & 0.17 & -0.98 & 0.17 & 0.16 & -0.45 & -0.45 \\
\hline AMYB3 & 0.23 & -0.79 & -0.44 & 0.28 & -0.6 & -1.16 \\
\hline DPEI & 0.29 & -0.85 & -0.48 & 0.05 & -0.71 & -1.06 \\
\hline FAP228 & 0.36 & -1.24 & -0.73 & 0.32 & -0.73 & -1.81 \\
\hline FAP228 & 1.59 & -0.66 & 0.33 & 1.75 & 0.75 & 0.75 \\
\hline$G A D 1$ & -0.81 & -0.24 & 0.36 & -0.29 & -0.21 & 0.82 \\
\hline$P G M I$ & 1.3 & 1.27 & 2.07 & 2.06 & 1.85 & 2.77 \\
\hline$G P M 2$ & 0.01 & -0.2 & 0.28 & 0.21 & 0.42 & 0.44 \\
\hline GTR11 & 0.18 & -1.15 & -0.59 & 0.19 & -0.44 & -1.41 \\
\hline GTR12 & 0.89 & 0.22 & 0.42 & 0.67 & 0.02 & 0.19 \\
\hline GTR 12 & 1.73 & -1.78 & 1.54 & 1.77 & 0.3 & 1.18 \\
\hline GTR 7 & 1 & -0.27 & 0.09 & 0.24 & -0.32 & -0.2 \\
\hline$H X K 1$ & -0.09 & -0.46 & 0.49 & -0.21 & -0.48 & -0.2 \\
\hline $\begin{array}{c}\text { beta-fructofur } \\
\text { anosidase }\end{array}$ & 0.63 & 0.25 & 0.19 & 0.71 & 0.52 & 0.86 \\
\hline$P G I 1$ & -0.88 & -0.77 & -0.28 & -0.62 & -0.85 & -0.52 \\
\hline PHOA & -0.24 & 0.07 & 0 & -0.06 & -0.14 & 0.6 \\
\hline РНОВ & -0.15 & -0.69 & -0.07 & -0.16 & -0.79 & -0.57 \\
\hline SBEI & 0.28 & -0.64 & -0.03 & -0.06 & -0.54 & -0.21 \\
\hline SBE2 & -0.1 & -1.28 & -0.39 & -0.01 & -0.8 & -0.88 \\
\hline$S B E 3$ & -0.7 & -0.97 & 0.01 & -0.36 & -0.62 & -0.18 \\
\hline SNE4 & 0.6 & 0.68 & 0.03 & 1.73 & 1.71 & 2.01 \\
\hline$S S S *$ & 0.23 & -0.3 & -0.1 & 0.45 & -0.12 & -0.16 \\
\hline SSS1 & -0.04 & -1.05 & -0.04 & 0.37 & -0.83 & -0.2 \\
\hline$S S S 2$ & -0.69 & -0.29 & 0.23 & -0.28 & 0.04 & -0.03 \\
\hline SSS3 & 0.13 & -0.28 & -0.17 & -0.01 & -0.25 & -0.48 \\
\hline SSS3 & 0.2 & -1.19 & -0.28 & 0.33 & 0.24 & -1.15 \\
\hline SSS 4 & -0.8 & -0.27 & -0.3 & -0.23 & -0.3 & -0.48 \\
\hline STAI & -1.56 & -1.04 & -0.38 & -0.81 & -0.84 & -0.29 \\
\hline STA11 & -0.32 & 0.12 & -0.09 & -0.59 & -0.11 & 0.36 \\
\hline STA3 & -2.13 & -2.56 & -1.47 & -1.77 & -2.06 & -1.54 \\
\hline STAG & -1.8 & -1.36 & -0.75 & -1.19 & -1.29 & -1.34 \\
\hline TPSI & -0.1 & -0.61 & -0.28 & -0.15 & -0.86 & -0.77 \\
\hline TPS2 2 & -0.21 & -0.27 & -0.02 & -0.41 & -0.29 & -0.64 \\
\hline TPS3 & 0.2 & -0.91 & -0.62 & -0.28 & -0.46 & -1.2 \\
\hline TPS3 & 1.01 & -0.36 & -0.22 & 0.33 & -0.15 & -0.39 \\
\hline$\alpha \alpha$-trehalase & -0.08 & 0.14 & 0.47 & 0.19 & 0.13 & 0.06 \\
\hline$U D G^{*}$ & -0.03 & -0.04 & -0.06 & -0.19 & -0.16 & 0.05 \\
\hline UGDI & -0.1 & -0.64 & 1.35 & 0.04 & -0.06 & 1.79 \\
\hline$U G D_{2}$ & -0.13 & -0.33 & 1.66 & -0.06 & 0.05 & 2.33 \\
\hline$U G P P$ & 0.31 & -0.54 & 0.04 & 0.35 & 0 & 1.5 \\
\hline
\end{tabular}

FIGURE 4 | Transcript levels of genes involved in starch biosynthesis in high-starch mutants by transcriptome analysis. Samples incubated in nitrogen-deficient TAP media for 3 and 7 days. Values indicate fold changes $\left(\log _{2}\right)$, which were calculated by comparison with each wild-type control

(Continued)

\section{FIGURE 4 | Continued}

grown in nitrogen-deficient TAP media. Red and green color indicate induction and reduction of gene expression, respectively. AGPase, ADP-glucose pyrophosphorylase; AGL, alpha-glucosidase; AMY, alpha-amylase, DPE, 4-alpha-glucanotransferase; FAP228, flagellar associated protein; GAD,

UDP-D-glucuronic acid decarboxylase; PGM, phosphoglucomutase; GTR, glycosyl transferase; HXK, hexokinase; PGI, phosphoglucose isomerase; $P H O$, starch phosphorylase; SBE, starch branching enzyme; SNE, NAD-dependent epimerase/dehydratase; SSS, soluble starch synthase; STA1, ADP-glucose pyrophosphorylase large subunit; STA11, 4-alpha-glucanotransferase; STA3, soluble starch synthase III; STA6, ADP-glucose pyrophosphorylase small subunit; TPS, trehalose-6-phosphate synthase/phosphatase; UGD, UDP-glucose dehydrogenase; UGP, UDP-glucose pyrophosphorylase.

\section{RNA Sequencing and Comparison of Gene Expression between Mutants}

To investigate mechanism of starch over-accumulation in mutants, comparative transcriptome analysis was performed. From each sample, over 13 million trimmed reads were generated using RNA sequencing (Table 1), which provide at least $10 \times$ transcriptome coverage. Trimmed reads from each sample were mapped to the $C$. reinhardtii genome database (version 5.5) in Phytozome. All samples had over 95\% mapped rates (Table 1). Three biological replicates were hired for reducing errors of sample preparation and sequencing. For comparison of gene expression between high-starch mutants and cc124 control, analysis of DEGs was performed (Figure 3). Sm142, Sm 162, and Sm 181 displayed 883, 571, and 518 up-regulated DEGs at day 3 after treatment of nitrogen starvation in comparison with cc124 control, respectively (Figure 3A and Supplementary Table 2). Twenty three up-regulated DEGs were commonly found in all mutants. Down-regulated DEGs at day 3 were also detected in Sm142 (953), Sm162 (782), and Sm181 (505); all mutants displayed 174 overlapped DEGs (Figure 3B and Supplementary Table 3). As shown in Figures 4, 5, total DEGs contained large number of genes encoding starch biosynthetic and glycolytic enzymes. Treatment of nitrogen starvation for 7 days reduced total number of up- and down-regulated DEGs compared to these from day 3, however, overlapped DEGs in mutants increased (data not shown). Up- and down-regulated DEGs from samples at day 3 were used for GO enrichment analysis using GO Database. Large numbers of DEGs at day 3 were classified as nitrogen compound metabolic process, cellular metabolic process, and transferase activity of GO Terms (Figure 3C and Supplementary Table 4).

\section{Expression Pattern of Genes Participated in Starch Biosynthesis and Glycolysis/Gluconeogenesis in Mutants}

To understand mechanism of starch over-accumulation in mutants, expression patterns of genes on starch biosynthesis were investigated by KEGG pathway mapping using transcriptome data (Figure 4 and Supplementary Table 5). High induction of phosphoglucomutase 1 (PGM1) encoding starch biosynthetic enzyme was found in all mutants at days 3 and 7 after 
treatment of nitrogen starvation (Figure 4). Whereas, transcript level of phosphoglucose isomerase 1 (PGI1) also decreased in all mutants at days 3 and 7. Surprisingly, key genes encoding starch biosynthetic enzymes, such as ADP-glucose pyrophosphorylase large subunit (STA1), soluble starch synthase III (STA3), and ADP-glucose pyrophosphorylase small subunit (STA6), were significantly down-regulated in all mutants (Figure 4). Quantitative RT-PCR analysis was performed to confirm expression levels of these genes. All mutants displayed down-regulations of STA1, STA3, and STA6 expression at day 3 after treatment of nitrogen starvation (Figure 5). Figure 4 also displays reductions of alpha- and beta-amylase (AMYA1, AMYA2, and AMYB1) transcript in mutant at days 3 and 7.

Expression levels of 48 genes which participate in glycolytic/gluconeogenic pathway including post-glycolytic process were determined between mutants by heatmap analysis (Figure 6 and Supplementary Table 6). Fructose 1,6-bisphosphate aldolase 1 and 2 (FBA1 and FBA2) expression were significantly reduced at day 3 in all mutants in comparison with cc124 control (Figure 6). FBA2 transcript was also down-regulated at day 7, whereas no consistent pattern of FBA1 expression was observed between mutants. Expression levels of phosphoenolpyruvate carboxykinase 1 (PCK1), mitochondrial pyruvate dehydrogenase complex 1 (PDC1), and acetyl-CoA synthetases 1 and 2 (ACS2 and $A C S 3$ ) were down-regulated at days 3 and 7 in all mutants (Figure 6). To confirm expression levels of these genes, quantitative RT-PCR analysis was carried out. Figure 7 shows expression patterns of PGM1, FBA1, FBA2, ACS2, and ACS3 at day 3 after treatment of nitrogen starvation in each mutant. PGM1 expression were highly up-regulated over fourfold in each mutant compared to a wild-type control. Transcript levels of FBA1, FBA2, and ACS2 were significantly reduced. Downregulations of $A C S 3$ transcripts were found in Sm162 mutant, but Sm142 and Sm181 showed slight reduction of ACS3 expression. Expression patterns of these genes confirmed by quantitative RT-PCR analysis were similar with these by the transcriptome analysis.

\section{DISCUSSION}

\section{PGM1 Plays a Key Role in Starch Accumulation in C. reinhardtii}

To investigate starch over-accumulation mechanism in highstarch mutants, 46 genes involved in starch biosynthetic pathway were selected from the RNA sequencing data by KEGG pathway mapping. Expression levels of these genes between mutants are shown in Figure 4. We observed a large amount of the transcript of PGM1 in all three mutants compared to a wild-type control under nitrogen-deficient condition (Figures 4, 6). PGM1 catalyzes the inter-conversion between glucose 1-phosphate and glucose 6-phosphate in starch biosynthetic pathway (Periappuram et al., 2000). Plastidial PGM1 appears to be an important enzyme in starch biosynthesis in higher plants as well as in C. reinhardtii. Overexpression of

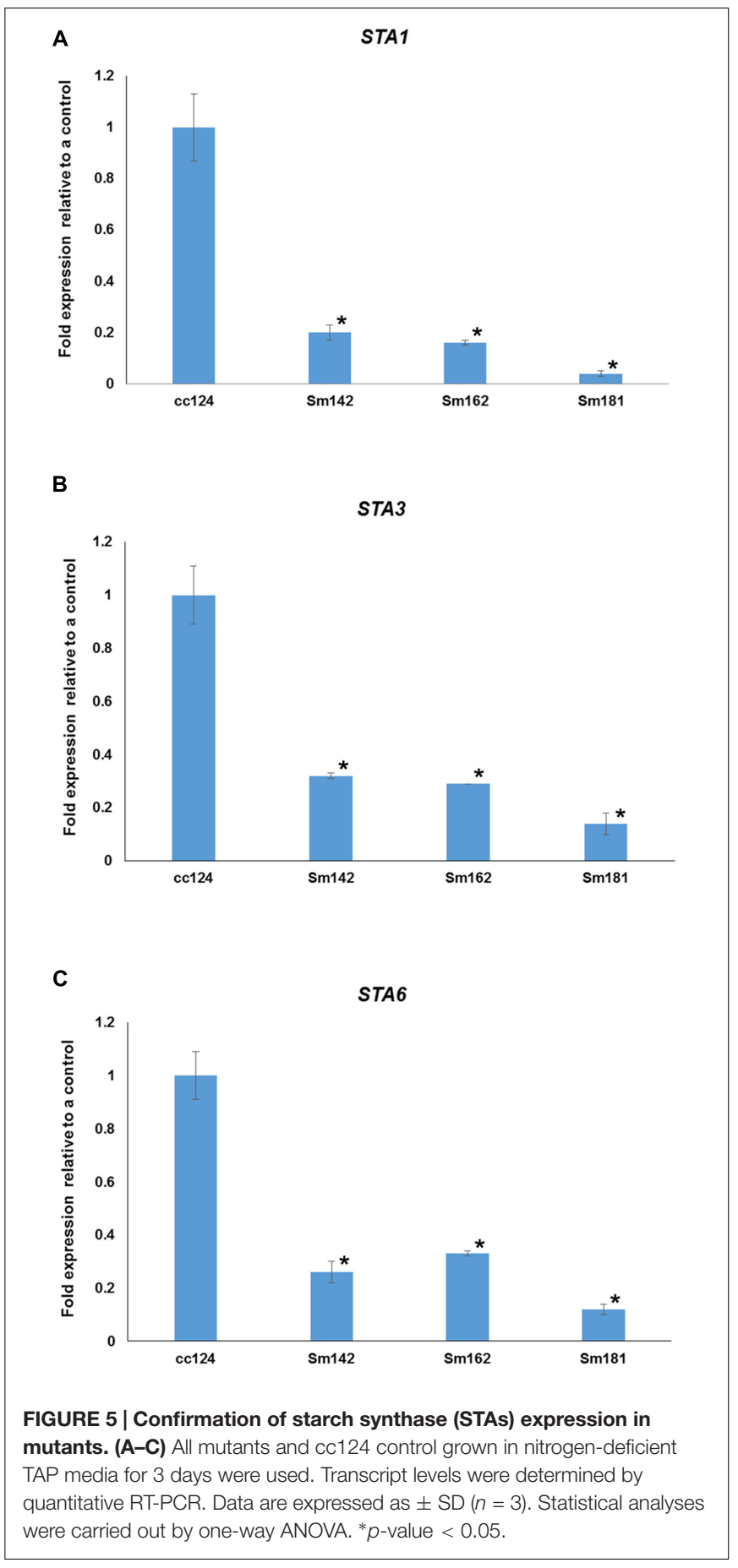

Arabidopsis plastidial PGM enhanced starch accumulation in tobacco (Uematsu et al., 2012) and the PGM1 knock-out mutant had lower starch content than a wild-type plant in Arabidopsis (Streb et al., 2009). Park et al. (2015) also observed that, at the initial stages of nitrogen deprivation, the PGM1 transcript was up-regulated compared to the control that was not under nitrogen deprivation in $C$. reinhardtii. These studies indicate that PGM1 is important in starch accumulation in both higher plants and green algae. Therefore, we suggest that up-regulation 
of PGM1 enhanced conversion of glucose 6-phosphate to glucose 1-phosphate, which resulted in starch over-accumulation in all mutants.

We were surprised that the transcript levels of other known genes essential for starch biosynthesis, such as STA3 and STA6, were reduced at days 3 and 7 after treatment of nitrogen deprivation in all mutants (Figures 4, 5). STA6 catalyzes the conversion of ATP and glucose 1-phosphate to ADP-glucose (Espada, 1962; Zabawinski et al., 2001), and STA3 mediates amylose synthesis from ADP-glucose (Fontaine et al., 1993). The activities of soluble starch synthases were in inverse proportion to starch content in higher plant (Park and Nishikawa, 2012). In C. reinhardtii, reduced expression of both soluble starch synthase and ADP-glucose pyrophosphorylase were also detected by increasing the time of nitrogen starvation (Park et al., 2015). Thus, it may be that expression of STA3 and STA6 depend on starch content. If so, down-regulation of STA3 and STA6 in mutants resulted from feedback regulation by the accumulated starch content.

\section{Suppression of Glycolytic Pathway Enhances Starch Accumulation}

Down-regulations of amylase alpha- and beta-amylase (AMYA1, $A M Y A 2$, and $A M Y B 1)$ transcripts were observed in mutant at days 3 and 7 (Figure 4). Alpha-amylase is a key enzyme that involves in degradation of storage starch granule during seed germination in higher plants (Lloyd et al., 2005). Beta-amylase regulates breakdown of transient starch granule in leaves. In leaves of Arabidopsis and potato, starch over-accumulation was observed by the absence of beta-amylase, due to slow starch degradation at the dark cycle (Scheidig et al., 2002; Fulton et al., 2008). Furthermore, hyper-accumulations of both starch and TAG were found in C. reinhardtii std1 mutant (Schulz-Raffelt et al., 2016). Therefore, reductions of alpha- and beta-amylase may affect to starch over-accumulation in mutants. Expression patterns of genes involved in glycolysis/gluconeogenesis were evaluated between mutants by heatmap analysis (Figure 6), because glycolytic pathway is working in conjunction with starch breakdown. Starch biosynthetic and glycolytic reaction are catalyzed by some of the same enzymes (Denis and Greyson, 1987). PGI1 are enzymes that participate in both glycolytic/gluconeogenic and starch biosynthetic pathway. PGI catalyzes the inter-conversion of glucose- 6 phosphate and fructose- 6 phosphate, which mediates connection of Calvin cycle to both starch biosynthetic pathway (Dietz, 1985). Arabidopsis mutant pgil showed low starch content in leave (Bahaji et al., 2015), which implies critical role of PGI1 in starch biosynthesis. Interestingly, in this study, reduced expression of PGI1 was determined in high-starch mutants by transcriptome and quantitative RT-PCR analysis (Figures 6, 7). Possible explanation of starch over-accumulation in mutants is that the down-regulation of PGI1 may reduce conversion of glucose6 phosphate to fructose- 6 phosphate in mutant cells, which could cause accumulation of glucose 6-phosphate. Accumulation of glucose 6-phosphate may have caused the up-regulation of $P G M 1$ that we observed (Figures 4, 6, 7), through feed-forward

\begin{tabular}{|c|c|c|c|c|c|c|}
\hline \multirow[b]{2}{*}{ Gene } & \multicolumn{3}{|c|}{ Day 3} & \multicolumn{3}{|c|}{ Day 7} \\
\hline & Sm142 & Sm162 & Sm181 & Sm142 & Sm162 & Sm181 \\
\hline$A C S 1$ & -0.53 & 0.21 & -0.03 & -0.27 & 0.29 & 0.13 \\
\hline${ }_{A C S 2}$ & -0.66 & -1.03 & -0.64 & -0.58 & -1.01 & -2.3 \\
\hline$A C S 3$ & -0.8 & -1.05 & -0.38 & -0.93 & -2.05 & -2.59 \\
\hline$A E P 1$ & -0.12 & -0.1 & -0.03 & 0.14 & -0.06 & 0.19 \\
\hline$A L D H$ & 1.07 & 0.23 & -0.62 & 1 & -0.02 & -0.54 \\
\hline DLAI & -0.49 & 0.57 & -0.43 & -0.38 & -0.03 & -0.48 \\
\hline DLA2 & -0.38 & 1.07 & 0.68 & -0.06 & 1.06 & 1.43 \\
\hline DLA3 & -0.63 & -0.2 & -0.67 & -0.59 & -0.34 & -0.45 \\
\hline DLD2 & 0.22 & -0.33 & -0.66 & 0.67 & 0.1 & -0.09 \\
\hline$F B A I$ & -1.2 & -1.37 & -1.56 & -0.39 & 1 & -0.18 \\
\hline$F B A 2$ & -1.08 & -0.93 & -0.71 & -0.27 & -0.45 & -0.21 \\
\hline$F B A 3$ & -2.39 & 0.39 & -0.6 & -1.13 & 0.73 & -0.52 \\
\hline$F B A 4$ & 0.4 & 0.74 & 0.49 & 0.11 & 0.03 & 1.01 \\
\hline$F B P 1$ & -1.28 & 0.18 & -0.47 & -0.63 & 0.3 & -0.34 \\
\hline$F D H I$ & -0.79 & -0.54 & -0.09 & -0.37 & -0.94 & -0.29 \\
\hline FDHI & -0.53 & -0.44 & 0.47 & -0.21 & -1 & 0.25 \\
\hline GAP1a & -0.84 & -0.26 & -0.6 & -0.72 & -0.68 & -0.27 \\
\hline$G A P 2$ & -0.05 & -0.2 & -0.12 & -0.21 & -0.25 & -0.28 \\
\hline$G A P N 1$ & -0.21 & -0.82 & -0.67 & -0.11 & -0.28 & -0.39 \\
\hline GCSL & -0.48 & -0.95 & -0.51 & -0.35 & -0.98 & -0.75 \\
\hline$P G M I$ & 1.3 & 1.27 & 2.07 & 2.06 & 1.85 & 2.77 \\
\hline GPM2 & 0.01 & -0.2 & 0.28 & 0.21 & 0.42 & 0.44 \\
\hline$H X K 1$ & -0.09 & -0.46 & 0.49 & -0.21 & -0.48 & -0.2 \\
\hline GPE & -1.15 & 0.23 & -0.08 & -0.51 & 0.46 & 0.83 \\
\hline GPE2 & -0.31 & -0.33 & 0.24 & -0.31 & 0.07 & 0.83 \\
\hline MINPP & -0.06 & -0.11 & -0.31 & 0.02 & -0.16 & 0.34 \\
\hline PCK 1 & -0.77 & -1.08 & -0.52 & -1.28 & -1.8 & -1.64 \\
\hline$P D C 1$ & -0.78 & -0.74 & -0.37 & -0.41 & -0.91 & -0.96 \\
\hline PDC3 & -0.6 & -0.41 & 0.28 & -0.05 & -0.2 & -0.14 \\
\hline PDH1a & -1.15 & -0.03 & -0.53 & -0.91 & -0.59 & -0.59 \\
\hline PDH 2 & -1.22 & 0.23 & -0.71 & -0.38 & 0.29 & 0 \\
\hline PFKI & -0.27 & -0.25 & 0.06 & -0.02 & -0.52 & -0.05 \\
\hline PFK 2 & 0.05 & -0.48 & 0.03 & 0.17 & -0.4 & 0.71 \\
\hline PFK 3 & 0.81 & -0.37 & -0.3 & 0.35 & -0.01 & -0.31 \\
\hline PFK 3 & 0.55 & 0.23 & -0.11 & -0.4 & -0.22 & -0.44 \\
\hline$P G H I$ & -0.6 & -0.07 & -0.13 & -0.26 & -0.27 & 0.1 \\
\hline PGII & -0.88 & -0.78 & -0.28 & -0.62 & -0.85 & -0.52 \\
\hline PGKI & -1.05 & -0.09 & -0.28 & -0.06 & 0.51 & 0.57 \\
\hline GPMI & -0.68 & -0.96 & 0.21 & -0.27 & -0.74 & -0.32 \\
\hline GPM2 & -0.56 & 0.01 & -0.15 & 0.09 & 0.39 & 1.5 \\
\hline GPM4 & -0.32 & -0.37 & -0.3 & -0.41 & -0.47 & -0.53 \\
\hline GPMS & 0.18 & 1.4 & 0.27 & 1.23 & 1.34 & 0.42 \\
\hline PYKI & -0.16 & 0.06 & -0.31 & -0.37 & -0.34 & -0.35 \\
\hline PYK2 & -0.38 & -0.63 & 0.11 & -0.29 & -0.82 & -0.72 \\
\hline РҮКза & 0.02 & -1.31 & -0.76 & -0.25 & -0.96 & -1.93 \\
\hline РYK4a & 0.07 & -1.69 & -0.56 & 0.31 & -0.59 & -0.74 \\
\hline PYK5 & 0.28 & -0.08 & -0.11 & 0.62 & 0.47 & 0.05 \\
\hline TPIC & -0.9 & 0.22 & -0.5 & -0.56 & -0.14 & -0.62 \\
\hline $\begin{array}{l}\text { FIGURE } 6 \text { | } \\
\text { glycolysis/g } \\
\text { analysis. Mu } \\
\text { TAP media fo } \\
\text { calculated by } \\
\text { indicate induc } \\
\text { acetyl-CoA s, } \\
\text { dehydrogena } \\
\text { fructose-1,6- } \\
\text { formaldehyde } \\
\text { dehydrogena } \\
\text { non-phospho } \\
\text { phosphogluc } \\
\text { 1-epimerase; } \\
\text { phosphoenol } \\
\text { dehydrogena } \\
\text { complex E1 } \\
\text { beta subunit; } \\
\text { phosphogluc } \\
\text { phosphoglyc } \\
\text { isomerase. }\end{array}$ & $\begin{array}{l}\text { ession } \\
\text { neoge } \\
\text { and w } \\
\text { nd } 7 \text { d } \\
\text { parisor } \\
\text { and re } \\
\text { tase; } A \\
\text { LA, dir } \\
\text { ospha } \\
\text { ydroge } \\
\text { APN, } \\
\text { ing; GC } \\
\text { ase; H, } \\
\text { PP, mu } \\
\text { rate cal } \\
\text { mplex } \\
\text { onent } \\
\text { phosp } \\
\text { somera } \\
\text { mutas }\end{array}$ & $\begin{array}{l}\text { vels o } \\
\text { sis in } \\
\text {-type } \\
\text { s. Valu } \\
\text { with ea } \\
\text { ction } \\
\text {, aldo } \\
\text { drolipo } \\
\text { aldola } \\
\text { se; GA } \\
\text { cerald } \\
\text { L, dihy } \\
\text {, hexo } \\
\text { ple ino } \\
\text { oxykin } \\
\text { DC, } m \\
\text { ha suk } \\
\text { ofructo } \\
\text {; PGK } \\
\text { PYK, }\end{array}$ & $\begin{array}{l}\text { genes } \\
\text { igh-st } \\
\text { ontrol n } \\
\text { s indica } \\
\text { wild-t } \\
\text { gene e } \\
\text {-1-epi } \\
\text { nide ac } \\
\text {; FBP, } \\
\text {, glyce } \\
\text { iyde } 3 \\
\text { rolipoyl } \\
\text { inase; } \\
\text { tol-poly } \\
\text { e; PDC } \\
\text { ochonc } \\
\text { init; } P D \\
\text { inase f } \\
\text { ohospl } \\
\text { ruvate }\end{array}$ & $\begin{array}{l}\text { icipate } \\
\text { mutan } \\
\text { cubat } \\
\text { d chan } \\
\text { ontrol. } \\
\text { sion, re } \\
\text { se; ALL } \\
\text { ansfer } \\
\text { se-1,6 } \\
\text { hyde } 3 \\
\text { bhate } \\
\text { droger } \\
\text { glucos } \\
\text { phate } \\
\text { chond } \\
\text { yruvate } \\
\text { ruvate } \\
\text { orotein } \\
\text { erate } 1 \\
\text { e; TPIC }\end{array}$ & $\begin{array}{l}\text { in } \\
\text { by tr } \\
\text { in nitr } \\
\text { (log } \\
\text { ed anc } \\
\text { pective } \\
\text { t, alde } \\
\text { e; FBA } \\
\text { ispho } \\
\text { hosph } \\
\text { hydros } \\
\text { se; PG } \\
6-p h o s \\
\text { ospha } \\
\text { al pyru } \\
\text { lehydr } \\
\text { ehydro } \\
\text { GH, } \\
\text { ase; G } \\
\text { triose }\end{array}$ & $\begin{array}{l}\text { sscriptome } \\
\text { en-deficient } \\
\text { which were } \\
\text { yreen color } \\
\text { ACS, } \\
\text { de } \\
\text { hatase; FDH, } \\
\text { e } \\
\text { nase } \\
\text { hate } \\
\text { se; PCK, } \\
\text { te } \\
\text { yenase } \\
\text { enase E1 } \\
\text { Jlase; PGI; } \\
\text { M, } \\
\text { osphate }\end{array}$ \\
\hline
\end{tabular}


A

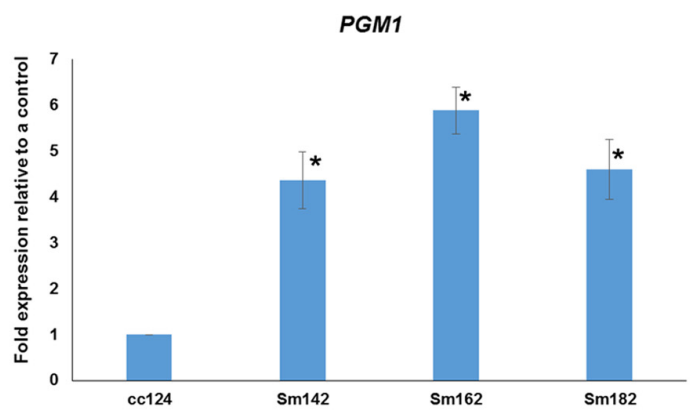

C

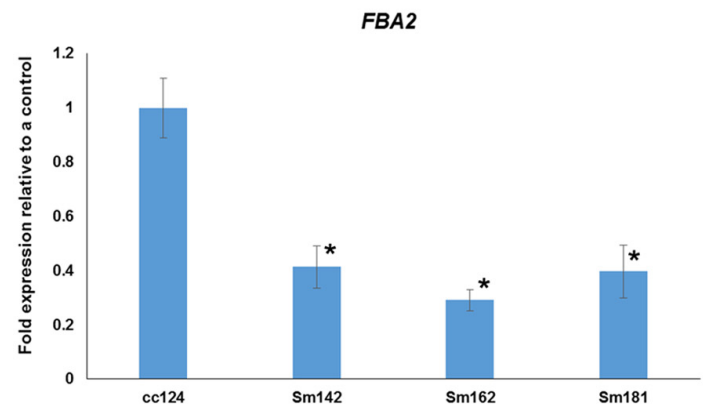

E

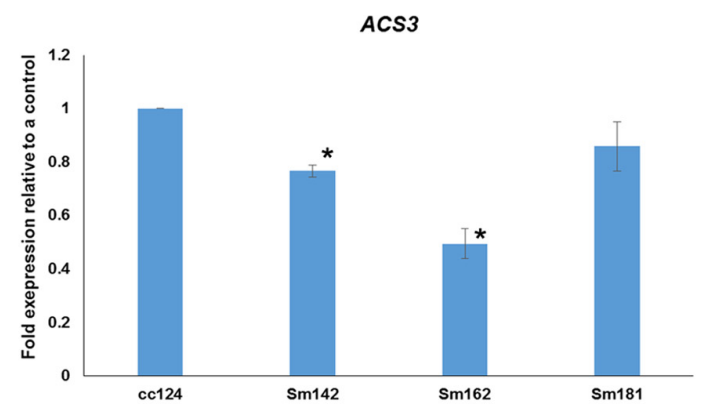

B

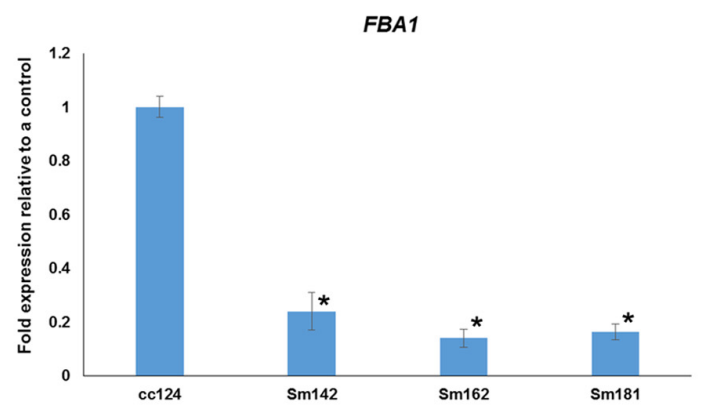

D

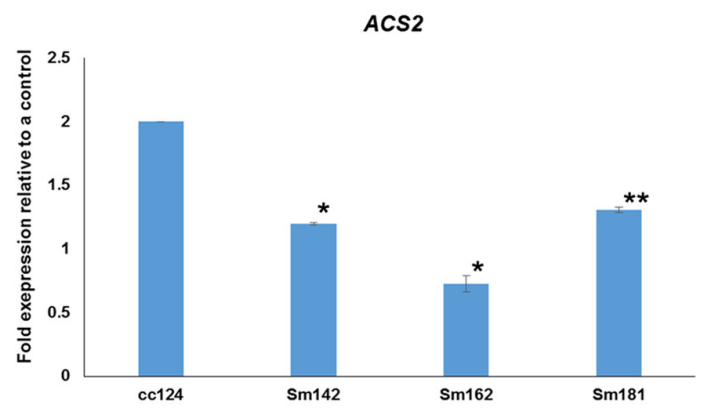

FIGURE 7 | Expressional confirmations for key genes involved in starch over-accumulation in mutants. (A-E) All mutants and cc124 control grown in nitrogen-deficient TAP media for 3 days were used. Transcript levels were determined by quantitative RT-PCR. Data are expressed as \pm SD $(n=3)$. Statistical analyses were conducted by one-way ANOVA. ${ }^{*} p$-value $<0.05,{ }^{* *} p$-value $<0.1$.

regulation. This, in turn, could lead to starch over-accumulation in mutants.

Under nitrogen deprivation, FBA1 and FBA2 expression were determined at day 3 in all mutants compared to a wildtype control (Figures 6, 7). Furthermore, FBA2 transcript was slightly down-regulated at day 7. FBA catalyzes conversion of fructose 1,6-bisphosphate to glyceraldehyde 3-phosphate and dihydroxyacetone phosphate in glycolysis (Rutter, 1964). An interesting point to note here is that Periappuram et al. (2000) reported the inhibition of PGM enzyme activity by fructose 1,6-bisphosphate and RuBP through in vitro enzyme assay, which implicates that fructose 1,6-bisphosphate may act as intermediate compound for Calvin cycle and starch biosynthetic pathway, especially control of PGM1 activity. This previous study supports our result that there is the correlation between PGM1, $F B A 1$, and FBA2 expression in glycolytic and starch biosynthetic pathway.

We did not detect any consistent patterns in the expression of FBA3 and FBA4 between mutants compared to expression of $F B A 1$ and FBA2 (Figure 6). In Arabidopsis, the FBA gene family is classified into plastidic and cytosolic type and expression patterns of these genes varied with developmental stages and stresses ( $\mathrm{Lu}$ et al., 2012). Recently, Park et al. (2015) analyzed transcriptome to nitrogen deprivation in $C$. reinhardtii and noted differential expression of FBA genes in response to time of nitrogen deprivation. The differential expression of FBA genes implicates 


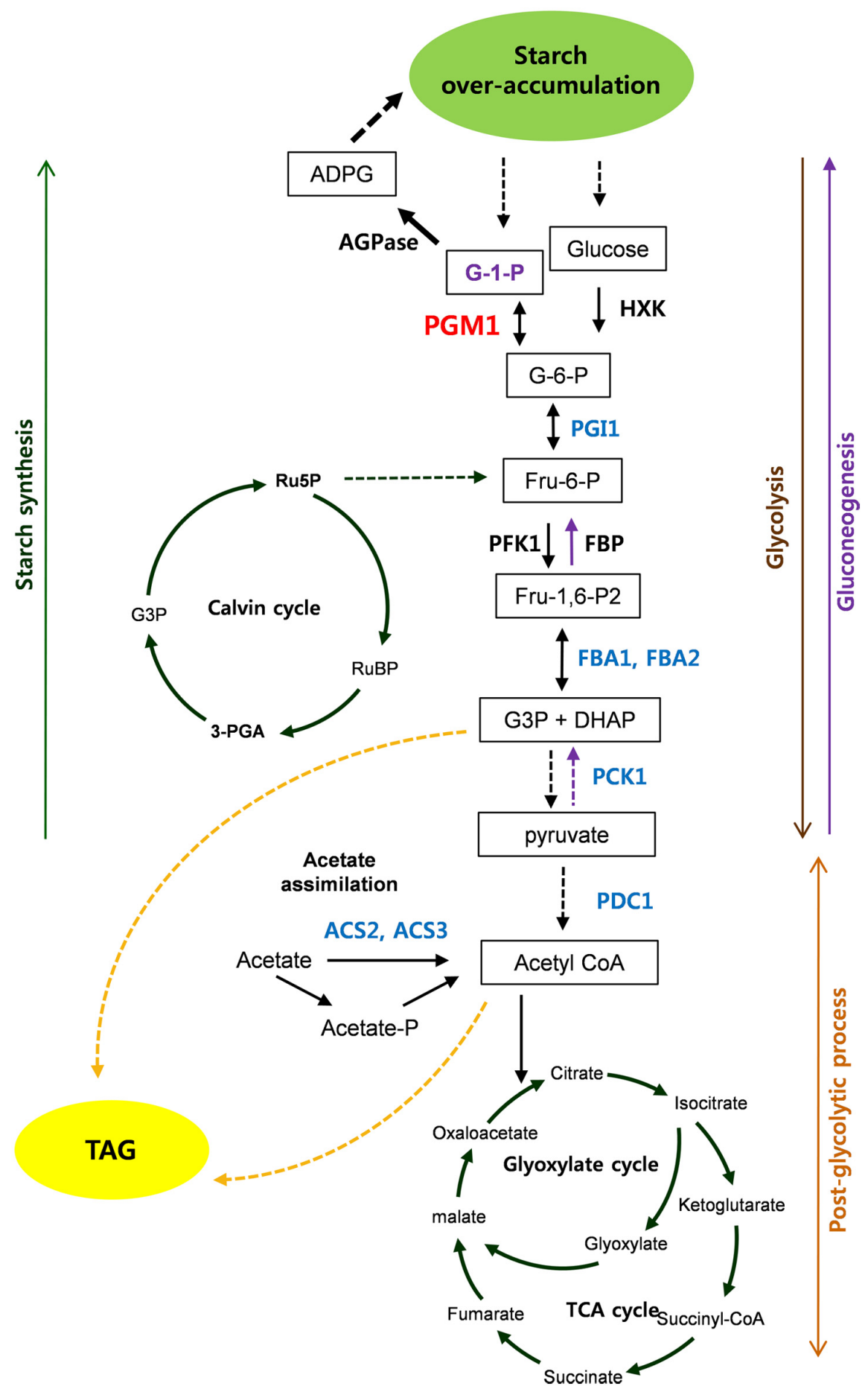

FIGURE 8 | Scheme of starch over-accumulation in Chlamydomonas reinhardtii high-starch mutants. Red and blue color indicate induction and reduction of gene expression, respectively.

functional diversity of FBA family in C. reinhardtii. Several gene transcripts encoding glycolytic/gluconeogenic enzymes (including post-glycolytic process) were significantly downregulated, such as PCK1, ACS2, and ACS3 (Figures 6, 7). Gluconeogenic enzyme PCK1 catalyzes oxaloacetate to phosphoenolpyruvate and ACS converts acetate to acetyl-CoA in acetate metabolism (Blaby et al., 2013). Similarly with our observation, Blaby et al. (2013) also reported inductions of PCK1 and ACS3 transcript in C. reinhardtii starchless mutant sta6 under nitrogen-deficient condition. Thus, the reason of 
reductions of $P C K 1, A C S 2$, and $A C S 3$ transcript in high-starch mutants may be due to inverse expression against starch content.

\section{CONCLUSION}

Based on our results, we propose the scheme of starch overaccumulation in $C$. reinhardtii mutants in Figure 8. In short, aberrant expression of PGM1, PGI1, FBA1, and FBA2, encoding starch biosynthetic and glycolytic enzymes, were detected in high-starch mutants. Reductions of PGI1, FBA1, and FBA2 expression caused down-regulation of glycolytic pathway, which may consequently result in accumulation of glucose 6-phosphate. Induction of PGM1 expression is likely due to feed-forward regulation by high level of glucose 6-phosphate content, which enhances starch over-accumulation. Therefore, we propose that PGM1, PGI1, FBA1, and FBA2 correlate each other and play key roles in starch accumulation in C. reinhardtii. Furthermore, PCK1, ACS2, and ACS3 seem to affect starch overaccumulation. This study provides fundamental information of glycolysis/gluconeogenesis and starch biosynthesis in green algae.

\section{REFERENCES}

Anders, S., and Huber, W. (2010). Differential expression analysis for sequence count data. Genome Biol. 11:R106. doi: 10.1186/gb-2010-11-10-r106

Bahaji, A., Sanchez-Lopez, A. M., De Diego, N., Munoz, F. J., Baroja-Fernandez, E., Li, J., et al. (2015). Plastidic phosphoglucose isomerase is an important determinant of starch accumulation in mesophyll cells, growth, photosynthetic capacity, and biosynthesis of plastidic cytokinins in Arabidopsis. PLoS ONE 10:e0119641. doi: 10.1371/journal.pone.0119641

Berg, J. M., Tymoczko, J. L., and Stryer, L. (2002). Glycolysis is an Energy-Conversion Pathway in Many Organisms. New York, NY: W H Freeman.

Blaby, I. K., Glaesener, A. G., Mettler, T., Fitz-Gibbon, S. T., Gallaher, S. D., Liu, B., et al. (2013). Systems-level analysis of nitrogen starvation-induced modifications of carbon metabolism in a Chlamydomonas reinhardtii starchless mutant. Plant Cell 25, 4305-4323. doi: 10.1105/tpc.113.117580

Buleon, A., Colonna, P., Planchot, V., and Ball, S. (1998). Starch granules: structure and biosynthesis. Int. J. Biol. Macromol. 23, 85-112. doi: 10.1016/S01418130(98)00040-3

Busi, M. V., Barchiesi, J., Martin, M., and Gomez-Casati, D. F. (2015). Starch metabolism in green algae. Starch 66, 28-40. doi: 10.1002/star.201200211

Chisti, Y. (2007). Biodiesel from microalgae. Biotechnol. Adv. 25, 294-306. doi: 10.1016/j.biotechadv.2007.02.001

de Faria Silva, C. E., and Bertucco, A. (2016). Bioethanol from microalgae and cyanobacteria: a review and technological outlook. Process. Biochem. 51, 1833-1842. doi: 10.1016/j.procbio.2016.02.016

Denis, D. T., and Greyson, M. F. (1987). Fructose 6-phosphate metabolism in plants. Plant Physiol. 33, 395-404. doi: 10.1111/j.1399-3054.1987.tb04306.x

Dietz, K.-J. (1985). A possible rate-limiting function of chloroplast hexosemonophosphate isomerase in starch synthesis of leaves. Biochem. Biophys. Acta 839, 240-248. doi: 10.1016/0304-4165(85)90004-2

Doana, Q. C., Moheimanib, N. R., Mastrangelo, A. J., and Lewis, D. M. (2012). Microalgal biomass for bioethanol fermentation: implications for hypersaline systems with an industrial focus. Biomass Bioenergy 49, 79-88. doi: 10.1016/j. biombioe.2012.08.022

Espada, J. (1962). Enzymic synthesis of adenosine diphosphate glucose from glucose 1-phosphate and adenosine triphosphate. J. Biol. Chem. 237, 3577-3581.

Fontaine, T., D'hulst, C., Maddelein, M. L., Routier, F., Pepin, T. M., Decq, A., et al. (1993). Toward an understanding of the biogenesis of the starch granule. Evidence that Chlamydomonas soluble starch synthase II controls the synthesis of intermediate size glucans of amylopectin. J. Biol. Chem. 268, 16223-16230.

\section{AUTHOR CONTRIBUTIONS}

J-WA and W-JJ designed experiments and wrote the manuscript. $\mathrm{KK}, \mathrm{SJ}$, and BL performed experiments. J-BK, YJ, H-IC, S-YK, and $\mathrm{G}-\mathrm{HC}$ commented on the manuscript and analyzed data. All authors contributed to writing the manuscript.

\section{ACKNOWLEDGMENTS}

This work was supported by the research program of KAERI, Republic of Korea and the Advanced Biomass R\&D Center (ABC) of Global Frontier Project funded by the Ministry of Science, ICT and Future Planning (ABC-2011-0031343).

\section{SUPPLEMENTARY MATERIAL}

The Supplementary Material for this article can be found online at: http://journal.frontiersin.org/article/10.3389/fmicb. 2017.00858/full\#supplementary-material

Fulton, D. C., Stettler, M., Mettler, T., Vaughan, C. K., Li, J., Francisco, P., et al. (2008). Beta-AMYLASE 4 , a noncatalytic protein required for starch breakdown, acts upstream of three active beta-amylases in Arabidopsis chloroplasts. Plant Cell 20, 1040-1058. doi: 10.1105/tpc.107.056507

Goodenough, U., Blaby, I., Casero, D., Gallaher, S. D., Goodson, C., Johnson, S., et al. (2014). The path to triacylglyceride obesity in the sta6 strain of Chlamydomonas reinhardtii. Eukaryot. Cell 13, 591-613. doi: 10.1128/EC. 00013-14

Harris, E. H. (2009). "Introduction to Chlamydomonas reinhardtii and its laboratory use," in The Chlamydomonas Sourcebook, (Amsterdam: Elsevier).

Huang, D. W., Sherman, B. T., and Lempicki, R. A. (2009). Systematic and integrative analysis of large gene lists using DAVID bioinformatics resources. Nat. Protoc. 4, 44-57. doi: 10.1038/nprot.2008.211

Johnson, X., and Alric, J. (2013). Central carbon metabolism and electron transport in Chlamydomonas reinhardtii: metabolic constraints for carbon partitioning between oil and starch. Eukaryot. Cell 12, 776-793. doi: 10.1128/EC.00318-12

Langmead, B., Trapnell, C., Pop, M., and Salzberg, S. L. (2009). Ultrafast and memory-efficient alignment of short DNA sequences to the human genome. Genome Biol. 10:R25. doi: 10.1186/gb-2009-10-3-r25

Li, Y., Horsman, M., Wu, N., Lan, C. Q., and Dubois-Calero, N. (2008). Biofuel from microalgae. Biotechnol. Prog. 24, 815-820. doi: 10.1021/bp070371k

Lloyd, J. R., Kossmann, J., and Ritte, G. (2005). Leaf starch degradation comes out of the shadows. Trends Plant Sci. 10, 130-137. doi: 10.1016/j.tplants.2005.01.001

Lu, W., Tang, X., Huo, Y., Xu, R., Qi, S., Huang, J., et al. (2012). Identification and characterization of fructose 1,6-bisphosphate aldolase genes in Arabidopsis reveal a gene family with diverse responses to abiotic stresses. Gene 503, 65-74. doi: 10.1016/j.gene.2012.04.042

Park, J. J., Wang, H., Gargouri, M., Deshpande, R. R., Skepper, J. N., Holguin, F. O., et al. (2015). The response of Chlamydomonas reinhardtii to nitrogen deprivation: a systems biology analysis. Plant J. 81, 611-624. doi: 10.1111/tpj. 12747

Park, Y. J., and Nishikawa, T. (2012). Characterization and expression analysis of the starch synthase gene family in grain amaranth (Amaranthus cruentus L.). Genes Genet. Syst. 87, 281-289. doi: 10.1266/ggs.87.281

Periappuram, C., Steinhauer, L., Barton, D. L., Taylor, D. C., Chatson, B., and Zou, J. (2000). The plastidic phosphoglucomutase from Arabidopsis. A reversible enzyme reaction with an important role in metabolic control. Plant Physiol. 122, 1193-1199. doi: 10.1104/pp.122.4.1193

Plaxton, W. C. (1996). The organization and regulation of plant glycolysis. Annu. Rev. Plant Physiol. Plant Mol. Biol. 47, 185-214. doi: 10.1146/annurev.arplant. 47.1.185 
Rutter, W. (1964). Evolution of aldolase. Fed. Proc. 23, 1248-1257.

Scheidig, A., Frohlich, A., Schulze, S., Lloyd, J. R., and Kossmann, J. (2002). Downregulation of a chloroplast-targeted beta-amylase leads to a starch-excess phenotype in leaves. Plant J. 30, 581-591. doi: 10.1046/j.1365-313X.2002. 01317.x

Schmollinger, S., Muhlhaus, T., Boyle, N. R., Blaby, I. K., Casero, D., Mettler, T., et al. (2014). Nitrogen-sparing mechanisms in Chlamydomonas affect the transcriptome, the proteome, and photosynthetic metabolism. Plant Cell 26, 1410-1435. doi: 10.1105/tpc.113.122523

Schulz, M. H., Zerbino, D. R., Vingron, M., and Birney, E. (2012). Oases: robust de novo RNA-seq assembly across the dynamic range of expression levels. Bioinformatics 28, 1086-1092. doi: 10.1093/bioinformatics/bts094

Schulz-Raffelt, M., Chochois, V., Auroy, P., Cuine, S., Billon, E., Dauvillee, D., et al. (2016). Hyper-accumulation of starch and oil in a Chlamydomonas mutant affected in a plant-specific DYRK kinase. Biotechnol. Biofuels 9:55. doi: 10.1186/ s13068-016-0469-2

Sharma, K. K., Schuhmann, H., and Schenk, P. M. (2012). High lipid induction in microalgae for biodiesel production. Energies 5, 1532-1553. doi: 10.3390/ en5051532

Siaut, M., Cuine, S., Cagnon, C., Fessler, B., Nguyen, M., Carrier, P., et al. (2011). Oil accumulation in the model green alga Chlamydomonas reinhardtii: characterization, variability between common laboratory strains and relationship with starch reserves. BMC Biotechnol. 11:7. doi: 10.1186/14726750-11-7

Singh, A. K., Elvitigala, T., Bhattacharyya-Pakrasi, M., Aurora, R., Ghosh, B., and Pakrasi, H. B. (2008). Integration of carbon and nitrogen metabolism with energy production is crucial to light acclimation in the cyanobacterium Synechocystis. Plant Physiol. 148, 467-478. doi: 10.1104/pp.108.123489

Spalding, M. H. (2009). "The $\mathrm{CO}_{2}$-concentrationg mechanism and carbon assimilation," in The Chlamydomonas Sourcebook, ed. D. B. Stern (Amsterdam: Elsevier), 257-302.
Streb, S., Egli, B., Eicke, S., and Zeeman, S. C. (2009). The debate on the pathway of starch synthesis: a closer look at low-starch mutants lacking plastidial phosphoglucomutase supports the chloroplast-localized pathway. Plant Physiol. 151, 1769-1772. doi: 10.1104/pp.109.144931

Streb, S., and Zeeman, S. C. (2012). Starch metabolism in Arabidopsis. Arabidopsis Book 10:e0160. doi: 10.1199/tab.0160

Uematsu, K., Suzuki, N., Iwamae, T., Inui, M., and Yukawa, H. (2012). Expression of Arabidopsis plastidial phosphoglucomutase in tobacco stimulates photosynthetic carbon flow into starch synthesis. J. Plant Physiol. 169, 14541462. doi: 10.1016/j.jplph.2012.05.008

Zabawinski, C., Van Den Koornhuyse, N., D’hulst, C., Schlichting, R., Giersch, C., Delrue, B., et al. (2001). Starchless mutants of Chlamydomonas reinhardtii lack the small subunit of a heterotetrameric ADP-glucose pyrophosphorylase. J. Bacteriol. 183, 1069-1077. doi: 10.1128/JB.183.3.10691077.2001

Zerbino, D. R., and Birney, E. (2008). Velvet: algorithms for de novo short read assembly using de Bruijn graph. Genome Res. 18, 821-829. doi: 10.1101/gr. 074492.107

Conflict of Interest Statement: The authors declare that the research was conducted in the absence of any commercial or financial relationships that could be construed as a potential conflict of interest.

Copyright (c) 2017 Koo, Jung, Lee, Kim, Jo, Choi, Kang, Chung, Jeong and Ahn. This is an open-access article distributed under the terms of the Creative Commons Attribution License (CC BY). The use, distribution or reproduction in other forums is permitted, provided the original author(s) or licensor are credited and that the original publication in this journal is cited, in accordance with accepted academic practice. No use, distribution or reproduction is permitted which does not comply with these terms. 